\title{
Article
}

\section{Generating sustainable collective action: Models of community control and governance of alcohol supply in Indigenous minority populations}

Shanthosh, Janani, Angell, Blake, Wilson, Andrew, Latimer, Jane, Hackett, Maree, Eades, Anne-Marie and Jan, Stephen

Available at http://clok.uclan.ac.uk/24789/

Shanthosh, Janani, Angell, Blake, Wilson, Andrew, Latimer, Jane, Hackett, Maree ORCID: 0000-0003-1211-9087, Eades, Anne-Marie and Jan, Stephen (2018) Generating sustainable collective action: Models of community control and governance of alcohol supply in Indigenous minority populations. International Journal of Drug Policy, 62 . pp. 78-85. ISSN 0955-3959

It is advisable to refer to the publisher's version if you intend to cite from the work. http://dx.doi.org/10.1016/j.drugpo.2018.09.011

For more information about UCLan's research in this area go to http://www.uclan.ac.uk/researchgroups/ and search for <name of research Group>.

For information about Research generally at UCLan please go to http://www.uclan.ac.uk/research/

All outputs in CLoK are protected by Intellectual Property Rights law, including Copyright law. Copyright, IPR and Moral Rights for the works on this site are retained by the individual authors and/or other copyright owners. Terms and conditions for use of this material are defined in the policies page. 


\section{Generating sustainable collective action: models of community control and governance of alcohol supply in Indigenous minority populations}

In October 2017, Australia succeeded in its campaign for a seat on the United Nations Human Rights Council. During the campaign, Australia committed to advancing the health and wellbeing of all Indigenous peoples in partnership with local communities. Given the international responsibilities bound to this role, including global leadership in advancing the health rights of marginalised populations, Australia must prioritise a plan of action to reduce the harmful use of alcohol in Aboriginal and Torres Strait Islander (hereafter Indigenous) communities.

The harmful use of alcohol is a major risk factor for chronic conditions such as liver disease, heart disease, stroke and cancer. Risky alcohol consumption and binge drinking also contributes to injuries and death from suicide and violence. Indigenous Australians are 1.6 times more likely than nonIndigenous Australians to abstain from alcohol use. (Australian Health Ministers' Advisory Council, 2017) Nevertheless, Indigenous Australians are disproportionately impacted by the harmful use of alcohol and alcohol-related harm. For example, Indigenous people are hospitalised for diagnoses related to alcohol at four times the rate of non-Indigenous people, most commonly for acute intoxication (59\%). (Australian Health Ministers' Advisory Council, 2017)

The World Health Organization has identified restrictions on the availability of alcohol as a "bestbuy" intervention. (World Health Organization, 2011) Despite the general effectiveness of such restrictions, their implementation within low-resource settings have been fragmented, short-lived and often harmful, even where regulatory strategies have involved some level of Indigenous participation. These initiatives, as we discuss in this paper, have demonstrated that the task of identifying models of participation that are effective, sustainable and acceptable is a difficult one. (Hudson, 2011) 


\section{Historical background}

There is significant cultural, linguistic and geographic diversity amongst Indigenous peoples. In addition, there are important differences in Indigenous peoples experiences of colonisation which have influenced community attitudes to leadership and law. (Brady, 2004) Despite the existence of an Indigenous civilisation over sixty thousand years old, at the time of British arrival in 1788, Australia was declared terra nullius ('empty land'). The absence of Indigenous rights to selfdetermination in the founding of the Australian nation-state contrasts in many ways with Indigenous experiences in the United States (US) where such rights were recognised in treaties with some Native American tribes and where tribal sovereignty is recognised in the US Constitution.

In Australia, Indigenous peoples were subjected to generations of racism and discrimination in laws and policies introduced at all levels of Australian government. This led to intergenerational trauma amongst many Indigenous people as well as a profound loss of kinship and culture. (Brady, 2004) For example, as a result of various assimilationist policies, Indigenous children (the Stolen Generations) were forcibly removed from their families between 1910 and 1970. Public health scholars hypothesise these experiences have contributed significantly to patterns of alcohol use in Indigenous communities. (Wilson, Stearne, Gray \& Saggers, 2010)

In addition, between 1838 and 1929, culturally and racially-based laws were introduced to prohibit the sale to and purchase of alcohol by Indigenous Australians. Prior to European contact, Indigenous Australians had some exposure to alcohol. However, the arrival of the 'First Fleet' significantly increased volume and availability, which in combination with prohibition laws led to a social imbalance between the Europeans and Indigenous Australians. For example, the addictive quality of alcohol, in concert with the significant access to alcohol enjoyed by European settlers led to the exchange of alcohol with Indigenous Australians as payment for labour and other forms of exploitation.(Saggers, 1998) In 1962, Indigenous Australians were given the right to vote in federal 
elections and throughout the remainder of the 1960s, state and territory laws and policies discriminating against Indigenous peoples were progressively repealed, including the exclusion of Indigenous Australians from the population census. During this time, alcohol prohibition laws were repealed. Subsequently, while many sectors of communities living in rural and remote townships with a significant Indigenous population support alcohol controls, some sectors have come to associate access to alcohol with the achievement of citizenship status. (Wilson, Stearne, Gray \& Saggers, 2010) For the latter group, more recent efforts to restrict alcohol have been seen as a throwback to the paternalism of the past. (Wilson, Stearne, Gray \& Saggers, 2010) Ultimately, communities do not necessarily have one consensual view on the use of regulation to manage alcohol consumption and alcohol-related harm. (d'Abbs, 1998) Certainly, not all will buy into a "public health dominant" view of the world and it can sometimes be at odds with the preferences and interests of some or many sections of communities.

Currently in Australia, Indigenous communities have limited scope for self-government. For example, there is no equivalent to the Tribal nation status affirmed in treaties with the United States, through which Indigenous people retain sovereign rights to enact and enforce policies on their lands, including the regulation of alcohol. In the absence of such regulatory power, many Australian community-based proponents of alcohol controls have engaged in a range of communitygovernment initiatives to tackle the issues of harmful alcohol use and alcohol-related harm in their communities.

In this paper we explore Australian examples of the governance models used to facilitate Indigenous participation and leadership when developing regulatory interventions to address harmful alcohol use and alcohol-related harm. We identify four distinct categories of governance of Indigenous communities: government initiated Indigenous community partnerships, Indigenous community coalitions backed by government intervention, government-facilitated Indigenous community led 
interventions, and interventions that have been conceived and implemented by Indigenous communities with minimal government intervention.

Each model is underpinned by specific governance arrangements which incorporate rules and processes that determine authority, accountability and Indigenous participation in decision-making. This paper seeks to trigger new insights into how these governance arrangements are situated along the spectrum of citizen participation. As such, the aim of this paper is to benchmark these models of Indigenous governance along a seminal theoretical framework in community engagement, Arnstein's ladder of participation. We begin with a brief explanation of Arnstein's conceptual framework and follow with a discussion of each model of governance.

\section{Arnstein's Ladder of Citizen Participation}

\section{Box 1: Arnstein's Ladder (Arnstein, 1969)}

\section{Box 2: Characteristics of Arnstein's rungs (adapted from Cummings, 2001)}

In her seminal 1969 work "A Ladder of citizen participation" Arnstein described the plight of the many marginalised populations ("have-nots") who are excluded, in subtle and explicit ways, from economic and political processes. In order to describe the reality of their lived experiences, Arnstein constructed a theoretical framework to assess level of engagement - the ladder of citizen participation. Seen together, the ladder rungs (Figures 1 and 2 ) represent a spectrum of engagement beginning with forms of non-participation and ending with full citizen control. (Arnstein, 1969)

1. Government initiated Indigenous community partnerships

Such partnerships are initiated by governments with communities to address the harmful use of alcohol and alcohol-related harm. The use of Alcohol Management Plans (AMPs) in Australia demonstrate recent and well-publicised examples. (Margolis, Ypinazar, \& Muller, 2007) 
In Queensland, under the Meeting Challenges Making Choices (MCMC) policy, AMPs allow individual communities to design community-specific AMPs through Community Justice Groups (CJGs). CJGs are composed of Indigenous leaders as well as government representatives and hold statutory powers to advise on the nature of AMPs.

Queensland's Liquor Act 1992 prescribes that the Minister must consult with CJGs and review their recommendations before the Minister can recommend regulations. However, failure to comply with these processes of consultation does not affect the validity of the regulation. (Queensland Liquor Act 1992)

Australia's Commonwealth government has introduced a similar AMP policy under the Stronger Futures in the Northern Territory Act 2012. The policy was introduced after 100 community consultations in which communities expressed concern over the high levels of harmful alcohol use. (Stronger Futures in the Northern Territory Act 2012)

Under the policy, the Minister may approve, vary or refuse to approve the AMPs. Thus, while the Commonwealth government states that policies are locally tailored whole of community plans, the Minister plays a significant role in regulating their use. Furthermore, in order to be approved, AMPs must fulfil five 'minimum standards' summarised below.

\section{Box 3: The Australian Commonwealth Government's five minimum standards}

Some Indigenous health scholars have characterised AMPs as a government initiative designed to work as closely as possible with communities to address levels of alcohol consumption and promote community safety. (Smith et al., 2013) Each AMP is unique to the community within which it operates. AMPs can include strategies for controlling alcohol supply (e.g. restrictions on sale or supply of alcohol, restrictions on hours of sale, restrictions on the types and amount of alcohol 
permitted to be sold to individuals and whole populations for on-license consumption within specific periods). It can also include strategies for reducing demand for alcohol (e.g. detoxification or treatment options for dependent drinkers, health promotion and education) and harm reduction strategies (e.g. support groups, sobering-up facilities, responses to violence and unsafe drinking).

\section{Funding of services tethered to supply restrictions}

The AMP model has been commended by community organisations for tethering demand and supply reduction strategies. However, a common concern for community members is that they often have little leverage to hold governments to account when programs are not funded or resourced (adequately or at all). For example, evaluations have shown that many proposals for health programs were not implemented. (d'Abbs, Ivory, Senior, Cunningham, \& Fitz, 2010; Senior et al., 2009) Indigenous health scholars have asserted that even where such policies incorporate a level of Indigenous self-determination, Australia's State and Territory governments have often abandoned their responsibilities and devolved community programs to communities without the trained personnel or resources to undertake these responsibilities. (Martin \& Brady, 2004) It has also been argued that due to the low cost of amending regulations and the higher cost of funding and staffing services in rural and remote communities, governments are quick to attend to legislative and policy amendments requested by community, but are slow to respond to the need for support services. (d'Abbs, 2011)

\section{Communities' challenges in obtaining government approvals}

In addition, while governments have claimed that all aspects of the AMPs have been community driven, it has been emphasised that some AMPs were introduced with little community consultation and with the process of designing interventions largely controlled by government. (Clough \& Bird, 2015; Clough et al., 2016; d'Abbs, 2011) As an example, whether communities were given the choice to implement restrictions on the supply of alcohol is hotly contested. Public health commentators argue that in the implementation of AMPs, government officials have insisted that 
alcohol restrictions should be put in place and also "set boundaries defining what [they] would and would not accept". (d'Abbs, 2011) Such an approach, it has been argued, represents the abandonment of a rights-based approach (whereby Indigenous Australians enjoy formal equality with non-Indigenous Australians with respect to alcohol) and a move towards governments using discriminatory powers to restrict alcohol. (d'Abbs, 2011)

The Australian Commonwealth government has also been questioned over why, despite a strong record of community engagement, it has blocked most community-developed AMP initiatives. In the regional centres of Alice Springs, Tennant Creek, Nhulunbuy, Darwin and Catherine, 80 communities and town camps were consulted on the draft minimum standards. Cross-sectoral feedback from community leaders, women's groups, health and safe house workers have contributed to the development of the policy, as well as implementation guidelines, engagement tools and guides for health and social service providers. (Commonwealth Government of Australia, 2013) However, seven years have passed since the implementation of the Commonwealth government's AMP policy and only one of eight community developed AMPs have received ministerial approval. When questioned by a federal Senator, the Department of the Prime Minister and Cabinet Portfolio responded that of the eight AMPs submitted, only the community of Titjkala met the minimum standards. (Senate Finance and Public Administration Legislation Committee, 2017)

Low levels of community awareness

An additional concern in relation to Queensland's MCMC partnership approach is that there have been low levels of awareness of the operation of AMPs in specific communities. (d'Abbs et al., 2010) A possible consequence is that community members risk fines or incarceration for contravening restrictions they did not know were in place. This raises questions as to whether the establishment of CJGs are an effective method of engaging communities.

Increased contact with the justice system 
Communities with AMPs have expressed serious concerns that due to the penalties attached to alcohol restrictions, residents who would not otherwise have had contact with the criminal justice system have obtained a criminal history. (Queensland Government Demography and Indigenous Statistics Team, 2013) These concerns are not unfounded. A 10 year (2003-2013) study launched by the Queensland Government in response to community concern found that of the 5676 individuals with a conviction for breaching AMP alcohol restrictions, 860 (15.2\%) had no convictions for other types of offences during the study period. 177 of those $860(20 \%)$ had subsequent convictions for a breach of alcohol restrictions. (Queensland Government Department of Treasury and Trade, 2013) Potentially exasperating such issues is the fact that penalties for individuals who contravene alcohol restrictions are far more severe for those in rural or remote populations where Indigenous peoples are predominant, than for many in the general Australian community. This is particularly true in major cities. In the Northern Territory, penalties for individuals who bring, possess, control or consume alcohol in breach of an alcohol protected area (where drinking alcohol is prohibited) are 100 penalty units or six months jail. (Northern Territory Government, 2017) If the quantity of alcohol is greater than $1350 \mathrm{ml}$ and involves supply or intended supply to a third person, the individual may be fined 680 penalty units or 18 months jail. (Northern Territory Government, 2017) As at 20172018 , a single penalty unit is $\$ 154$. (Northern Territory Department of Treasury and Finance, 2017) By contrast, local governments in the city of Sydney have introduced alcohol-free zones which restrict the consumption of alcohol on public streets and in parks. Contravention of the restrictions can result in alcohol being confiscated or disposed of and a $\$ 200$ fine if the individual is found to be obstructing police. (North Sydney Council, 2017)

For these reasons and others, AMPs have been seen by some members of the community as discriminatory. An AMP on Palm Island, Queensland has been the subject of a High Court case which examined whether the AMP restrictions engaged Section 10 of the Racial Discrimination Act 1975 (RDA). In that case, the appellant was found with two $1125 \mathrm{ml}$ bottles of bourbon and rum. A \$150 
fine was to be paid within two months or the appellant faced imprisonment in default of payment. (Joan Monica Maloney v The Queen [2013] HCA 28)

That case explored whether alcohol restrictions could be justified as a special measure within the meaning of Section 8 of the Racial Discrimination Act which prescribes that special measures "may be necessary in order to ensure such groups or individuals have equal enjoyment or exercise of human rights and fundamental freedoms". (Racial Discrimination Act 1975) The appellant argued that the intention of the special measures exception was to protect the human rights of the intended beneficiaries. Instead, it was argued, the Palm Island AMP effectively impaired individuals' right to equality before the law and the enjoyment of the right to property for members of a racial group. Indeed, legal precedent had established that a law that punishes and restricts behaviour of the beneficiaries and cannot be linked with predictable improvements for that group cannot be deemed a special measure. However, in this case, the High Court upheld the conviction, expressing that although laws prohibiting an Indigenous person from owning alcohol would ordinarily be a discriminatory limitation on the human right to own property - and in contravention of the RDA the special measures principle sufficiently justified the prohibition of alcohol. Further, the fact that Indigenous consultation had been built into the AMP model helped to justify the government's implementation of the intervention as a special measure.

Government-facilitated community partnerships appear to closely resemble Arnstein's 'partnership' rung. Queensland's and the Australian Commonwealth Governments' AMP policies involve the redistribution of power (albeit unequal) through negotiation between CJGs and government powerholders who agree to share decision making responsibilities.

Arnstein describes in relation to the 'partnership' rung that typically, after ground rules are set, they are not subject to unilateral change. In the context of AMP policies, AMPs are to be amended at the request of government powerholders in collaboration with communities. However, there are minimal safeguards to ensure community recommendations are actioned. Where there is conflict 
between CJGs recommendations and government regulators, communities have little bargaining power to negotiate mutually acceptable solutions due to the fact that regulatory power is held by government.

For this reason, some may consider such government-facilitated community partnerships to fall short of the partnership rung. For instance, the ability for governments to ultimately determine whether the nature of AMPs are sufficient and appropriate has much in common with consultation whereby opinions are invited with no guarantee of action and placation, as government powerholders can judge the feasibility of communities' advice.

2. Indigenous community coalitions backed by government intervention

This model of governance represents grass roots community coalitions that through community campaigning and government lobbying have achieved regulatory backing. In Tennant Creek, NT, a community coalition secured widespread community support for alcohol restrictions. These restrictions led to significant Territory-wide reductions in pure alcohol consumption. (Gray, 2000) In Groote Eylandt, local community leaders engaged in consultations with local police, the Anindilyakwa Land Council and mining company GEMCO. Together, the coalition designed and implemented an Alcohol Management System whereby takeaway liquor purchases required a liquor permit issued by the NT Licensing Commission on the recommendation of a local Permit Committee. The intervention also enjoyed the backing of the majority of the community and was successful in producing significant reductions in alcohol-related violence. (Conigrave, 2007)

Another community coalition in Fitzroy Crossing proved to be highly organised in having their priorities met. After multiple suicides in the community (50 in the 12 months between 2005-6), the Marninwarntikura Fitzroy Women's Resource Centre successfully lobbied the Director of the West Australian Liquor Licensing Authority for an initial 12-month trial of alcohol restrictions. (Australian 
Human Rights Commission, 2010; Elliott, Latimer, Fitzpatrick, Oscar, \& Carter, 2012) Ms June Oscar, a Bunuba woman born in Fitzroy, then CEO of the Resource Centre, described that "this [Fitzroy] is a community that has suffered too many preventable deaths. Many of those deaths were suicides and, from the coroner's inquiry and the toxicology reports, many of the people that we lost had high levels-lethal amounts-of alcohol in their blood. Whether people live or die in that state was something that this community had to face up to and to make decisions to change, because we could not and we will not continue to see our family members die because of the oversupply of alcohol that was happening here in Fitzroy".(Commonwealth Government of Australia, 2010)

The alcohol restrictions were seen as a "remarkable achievement" and "a major step in reducing the impact of alcohol-fuelled violence within families across the Fitzroy Valley" by Ms Emily Carter, then Chairperson (now CEO) of the Resource Centre and a Gooniyandi Kija woman from the central Kimberley region.(Marninwarntikura Fitzroy Women's Resource Centre, 2018) The Resource Centre included women from four language groups (Bunuba, Gooniyandi, Walmajarri and Wangkatjunga) and the Kimberley Aboriginal Law and Culture Centre (KALACC), a Kimberley-wide Aboriginal organisation promoting law and culture of the region's language groups.

Prior to proposing restrictions, meetings were held with the Director and all key stakeholders, senior representatives from Kimberley Aboriginal Law and Culture Centre, representatives from joint venture partners (an Aboriginal corporation that owns the Fitzroy River Lodge and the Crossing Inn), Council representatives and health and child protection services. The coalition brought together and leveraged the resources of diverse sectors of the community (e.g. police, Indigenous services, faithbased institutions and professional organisations). Coalition committees incorporated wider community input through bush meetings. This critical mass of support triggered government backing of restrictions and enabled proponents to withstand and overcome strong opposition and vilification. (Commonwealth Government of Australia, 2010) 
Interestingly, the introduction of alcohol restrictions in Fitzroy Crossing did not occur as a result of consensus. Despite significant efforts to address the concerns of those opposing the alcohol restrictions and to correct misinformation that was perceived to have fuelled dissent through media campaigns and discussion forums, it was not possible to achieve consensus. (Australian Human Rights Commission, 2010) Community opposition remained throughout the process. Some of those dissenting argued that such policies were paternalistic, discriminatory and did not align with the principles of Indigenous self-determination. However, Indigenous leaders such as former and current Aboriginal and Torres Strait Islander Social Justice Commissioners Mick Gooda and June Oscar formed the view that the devastating effects of alcohol-related death, injury and violence in Fitzroy Crossing justified the use of geographic restrictions that treated predominantly Indigenous populations differently to the general Australian population. Furthermore, those leading the campaign for Fitzroy's restrictions have suggested that the lack of community consensus should not be a barrier to implementing restrictions, particularly for communities in crisis where immediate relief from alcohol-related harm is necessary. (Australian Human Rights Commission, 2010) However, unlike the earlier example of the MCMC's CJGs, these types of coalitions generally do not have rights to shared decision making. Community recommendations regarding the nature of alcohol controls do not need to be considered in order for governments to act. As a consequence, communities must rely on governments to act on community-developed strategies, such as the incorporation of programs alongside restrictions to safeguard vulnerable members of the community from unintended consequences of alcohol restrictions.

The communities of Port Augusta, Katherine and Alice Springs have successfully campaigned for the incorporation of early intervention, prevention, education and health promotion programs (e.g. providing training for health professionals to better target and intervene with risky drinkers) alongside alcohol restrictions. (Port Augusta City Council, 2010; d'Abbs, 2011; Senior, Chenhall, Ivory, \& Stevenson, 2009) However, in Fitzroy Crossing community members have expressed concerns that 
as restrictions were not implemented in combination with rehabilitation services, those experiencing alcohol dependency in Fitzroy Crossing were replacing alcohol with ganja (marijuana). (Hudson, 2011)

Community coalitions backed by government intervention appear to align with Arnstein's placation rung. In the scenarios discussed, citizens have a degree of influence, in that they are able to advise on the nature of restrictions. However, government powerholders retain the right to judge the legitimacy of the advice. Arnstein describes this right of powerholders as detracting from genuine citizen participation. However, the case of Fitzroy Crossing demonstrates that where community representatives such as the Marninwarntikura Fitzroy Women's Resource Centre request specific regulatory action of governments and decision makers respond to these requests on an equal basis, communities may stand to benefit in terms of health and social outcomes.

\section{Government-facilitated Indigenous community-led}

Typically, interventions under this model of governance have involved government facilitated policy arrangements that have been adopted by local, community-based stakeholders. These have sometimes been called community-based (as opposed to community-owned) interventions. (Blagg, 2008; Blagg \& Valuri, 2003)

For instance, in Queensland and the Northern Territory, governments have introduced legislation to allow licensed premises to be owned, operated and administered by Indigenous community stakeholders. Under this system, community councils designate liquor license holders to control local alcohol supply. Licensees can apply alcohol restrictions that reflect the best interests of the community, such as targeting at-risk populations such as those experiencing substance abuse problems using mechanisms such as limits on amounts of liquor purchased, hours of sale, day-caps on alcohol purchases and bans on problem drinkers imposed by the holder/s of the license. Proponents have argued that such a system facilitates a safe social club where alcohol can be consumed safely. (Hudson, 2011) In encouraging moderate consumption, it has been promoted by 
local authorities, town councillors and politicians as "the imagined antidote to a myriad of drinking problems, including binge drinking, drink-driving, migration to urban areas and squatting in towns". (Brady, 2014) Further, as supply restrictions are locally developed, in theory such clubs can be promoted as 'expressions of self-determination'. (d'Abbs, 1998)

Bodies such as the Central Australian Aboriginal Congress (CAAC) have previously supported the social club model, provided they are well-regulated. For instance, the CAAC have argued that the local population should consent to the presence of licensed clubs with proposals for community approval held by secret ballot. (Central Australian Aboriginal Congress, 2009) Further, it has been suggested that licensed clubs should ensure safety and specific management policies (e.g. policies prohibiting the serving of alcohol to high-risk individuals) are adhered to. (Central Australian Aboriginal Congress, 2009)

However, while such mechanisms have delegated limited regulatory power to community representatives, it is imperative that such models incorporate the preferences and needs of whole communities rather than merely those who stand to benefit from the sale of alcohol. In practice, examples such as the social club model show that without this process of engagement, some models of delegated power can institutionalise disadvantage. In many cases, communities have had little control over the presence and operation of such venues. The community-ownership model has often given rise to conflicts of interest between profit raising and protecting at-risk members of the population. Heavy drinkers have become dependent on canteens, and licensees dependent on heavy drinkers for their economic prosperity and funds for community infrastructure and development. (d'Abbs, 1998) Social and health service providers have argued that social services were reliant on such profit raising and yet, alcohol-related harm was driving the need for these services. (Hudson, 2011) It has been argued that the implementation of social clubs has allowed governments to abdicate responsibility for preventing and treating the health and social consequences of alcoholrelated harm by devolving responsibility of crucial public health services to communities that may 
have neither the resources nor the trained personnel needed to effectively deliver them. (Martin \& Brady, 2004) Further, weak accountability requirements and under-resourced, poorly developed and trained administrative infrastructure in some communities have exacerbated the monopolistic control enjoyed by licensees. In some cases, licensees have exploited the low level of literacy of populations which have placed them in a weak position to scrutinise management. (d'Abbs, 1998) Moreover, these issues highlighted by public health academics over more than two decades often resulted in little government action. (d'Abbs, 1998; Brady, 2010)

This model of government closely resembles Arnstein's concept of delegated power. Social clubs have given community stakeholders dominant decision making authority over the control of alcohol supply and responses to alcohol-related harm. The community-ownership model gives local stakeholders genuine specified powers and these stakeholders hold significant responsibility to assure accountability of the social club program to them, whilst government powerholders have final veto powers.

Arnstein argues that the ability for community stakeholders to be able to design, implement and enforce interventions represents one of the highest forms of community empowerment. However, the example of social clubs highlights how perverse incentives can lead to delegated power that is harmful to communities.

4. Indigenous community-conceived and implemented

Indigenous community-conceived and implemented interventions (sometimes called communityowned) generally involve minimal government involvement. (Blagg, 2008; Blagg \& Valuri, 2003) To a large extent, responsibilities associated with designing, implementing, maintaining and enforcing controls are assumed by community members.

The use of night patrols (also known as youth, women's, bare-foot and street patrols) in Australia are one such example. Night patrols are context-specific and vary significantly in form and function 
across Australia's rural and remote Indigenous communities. While there is no standard definition, they often involve community leaders using dispute resolution and mediation methods to promote peace, security and safety within the community. Current and past models of night patrols sought to minimise substance abuse and to intervene to prevent self-harm and family violence.

Communities attribute the success of night patrols to the freedom that community leaders have in developing and implementing strategies that align with Indigenous conceptualisations of family, kinship and culture, ways of knowing, being and doing. For instance, women were often more comfortable taking leadership in matters concerning other women in the community. Further, the focus on "looking after" family as opposed to banning or controlling specific behaviours through coercive measures contributed to the legitimacy, trust and acceptability of the night patrol amongst community members. (Turner-Walker, 2012) Additionally, the intricate knowledge of village relationships, cultural knowledge and standing within the community helped to sustain the operation of the night patrol and supported its legitimacy amongst community members.

There is considerable disagreement over whether community-conceived and implemented night patrols benefit from government regulation and resourcing. The responsibilities attributed to night patrollers are often extremely resource-intensive - travelling large distances on foot or in a vehicle, the sacrifice of family time and long hours spent negotiating agreements to avoid the escalation of conflict. For these reasons, some community organisations such as the Tangentyere Council (the major service delivery agency in Alice Springs) have suggested that night patrols are most effective when based on Aboriginal roles and relationships with the support of police and courts, "used as a negotiation tool". (Tangentyere Council Northern Territory, 2002) However, others have argued that the use of government resources to support patrols means they can no longer fulfil the role of "looking after" family. It is argued that this reduces its effectiveness and undermines the operation of the patrol and its credibility. (Turner-Walker, 2012) 
Yet, without government regulation, public health academics have argued that night patrols are difficult to maintain and enforce. A report found that in one Northern Territory community, a particular challenge faced by community members was that they could not physically intervene or confiscate alcohol. Further, they had been warned by police that in some circumstances confiscation could constitute theft. (Hudson, 2011)

Such community-conceived and implemented interventions can be categorised under Arnstein's citizen control rung as community members govern the night patrol program and are in full charge of managerial aspects. Further, they are able to negotiate the conditions under which 'outsiders' may contribute to or change these conditions - for example government powerholders in funding night patrol activities.

Citizen control in the context of alcohol control in Indigenous minority populations, appears to be the ideal. Communities can frame their goals in ways that are community-centred rather than statederived. In addition, regulatory activities can be carried out in accordance with procedures that reflect Indigenous conceptions of health, which often privilege rehabilitation and protecting peaceful, sustainable relationships with family and community over punitive consequences. The more coercive menu of regulatory instruments used by governments to regulate alcohol supply, such as prohibition on the possession and consumption of alcohol often conflict with such values.

At the same time, without government resourcing, communities can incur significant costs (e.g. costs of volunteered time) in order to ensure program sustainability. As such, examples such as night patrols show that even successful forms of citizen control may require a basic framework of government support and regulation. For these reasons, the governance arrangements underpinning citizen control may not always be considered the communities' ideal.

Conclusions 
While Arnstein's ladder of participation, sees citizen control as the highest level of citizen engagement, we argue that there is no 'one size fits all' when it comes to governance arrangements and that meaningful citizen engagement can be achieved in many forms. In order to achieve this, governments will need to negotiate models that are acceptable and sustainable. Indigenous participation will need to balance the need to elicit a broad base of views pertaining to alcohol regulation without undermining existing communities' systems of governance, which may not necessarily be representative. As the needs and circumstances of community members evolve, the public health research community must continue to elevate their perspectives with regard to the governance arrangements detailed in this paper, as well as the rules and processes that determine authority, accountability and Indigenous participation in decision-making.

In their approach, governments at all levels need to seek out and act upon community preferences regarding appropriate and acceptable consultation. It is vital that consultation promotes respect and reciprocity and involves working together on an equal basis. In addition, governance mechanisms, through effective monitoring and evaluation, must facilitate the accountability of community and government representatives to affected communities. What we suggest is that in relation to programs such as alcohol restrictions where there are likely to be conflicting interests, the role of government needs to be strong in mediating these interests through regulatory action on policing; many of these fall into the first two and to some extent our third model of governance. In contrast there are programs which seem more appropriate in the fourth model - such as night patrols where there are fewer conflicting interests at stake and as such the role of government is in facilitation and coordination.

Perhaps most importantly, it is essential that communities are armed with the human and financial resources necessary to effectively treat and prevent harmful alcohol use and alcohol-related harm. To curtail the many potential unintended consequences of supply restrictions, health and social programs need to be funded and made accessible. Ultimately, to meaningfully impact Indigenous 
health and social and emotional wellbeing, Australian governments will need to commit to a

transparent and responsive approach to Indigenous engagement in alcohol control.

References

Arnstein, S. R. (1969). A ladder of citizen participation. Journal of the American Institute of planners, 35(4), 216224.

Australian Human Rights Commission (2010). Social justice report 2010. Retrieved 10th October 2017 from http://www.humanrights.gov.au/our-work/aboriginal-and-torres-strait-islander-socialjustice/publications/social-justice-report-1

Australian Broadcasting Corporation. Federal Minister lends support to alcohol restrictions in Kimberley (2016). Retrieved $10^{\text {th }}$ October 2017 from http://www.abc.net.au/news/2016-03-18/nigel-scullionlends-support-to-alcohol-restrictions-in-kimberl/7256120

Australian Health Ministers' Advisory Council. Aboriginal and Torres Strait Islander Health Performance Framework 2017 Report. Retrieved 9th January 2018 from https://www.pmc.gov.au/sites/default/files/publications/2017-health-performance-frameworkreport.pdf

Brady, M. (2004). Indigenous Australia and alcohol policy: meeting difference with indifference. Australian Journal of Social Issues, 39(4), 480-480.

Blagg, H. (2008). Crime, Aboriginality and the decolonisation of justice. Sydney: Hawkins Press.

Blagg, H., Valuri, G. (2003). An overview of night patrol services in Australia: Attorney-General's Department.

Brady, M. (2014). Lessons from a history of beer canteens and licensed clubs in Indigenous Australian communities: Centre for Aboriginal Economic Policy Research, Research School of Social Science, College of Arts and Social Science, The Australian National University.

Brady, M., (2010). On-and off-premise drinking choices among Indigenous Australians: The influence of sociospatial factors. Drug and alcohol review, 29(4), 446-451.

Cummings, J., (2001). Engaging stakeholders in corporate accountability programmes: A cross-sectoral analysis of UK and transnational experience. Business Ethics: A European Review, 10(1), 45-52.

Clough, A.R., Bird, K. (2015). The implementation and development of complex alcohol control policies in indigenous communities in Queensland (Australia). International Journal of Drug Policy, 26(4), 345351.

Conigrave, K. M., Proude, E., d'Abbs, P (2007). Evaluation of the Groote Eylandt and Bickerton Island Alcohol Management System. A report produced for the Department of Justice, Northern Territory Government. Sydney: Royal Prince Alfred Hospital.

Commonwealth Government of Australia. House of Representatives Standing Committee on Aboriginal and Torres Strait Islander Affairs. Involvement of Indigenous juveniles and young adults in the criminal justice system (2010). Retrieved 12 June 2018 from https://www.aph.gov.au/binaries/hansard/reps/commttee/r12898.pdf.

Commonwealth Government of Australia. Stronger Futures in the Northern Territory (Alcohol Management Plans) Explanatory Statement. Retrieved 12 June 2018 from https://www.legislation.gov.au/Details/F2013L00290/Explanatory\%20Statement/Text.

Central Australian Aboriginal Congress. Position Paper Aboriginal Social Clubs. Retrieved 10th October 2017 from https://parliament.nt.gov.au/_data/assets/pdf_file/0007/363229/Submission_Number_24_Attachm ent_G_Aboriginal_Social_Clubs.pdf

Clough, A. R., Margolis, S. A., Miller, A., Shakeshaft, A., Doran, C. M., McDermott, R. et al.(2016). Alcohol control policies in Indigenous communities: a qualitative study of the perceptions of their effectiveness among service providers, stakeholders and community leaders in Queensland (Australia). International Journal of Drug Policy, 36, 67-75.

Port Augusta City Council. Port Augusta Community Alcohol Management Plan 2016-2019. Retrieved $10^{\text {th }}$ October 2017 from

http://www.portaugusta.sa.gov.au/webdata/resources/files/AR10_2383_Port_Augusta_Community _Alcohol_Management_Plan_2010_-_2015_-_Final_Draft_PDF.pdf

d'Abbs, P. (1998). Out of sight, out of mind? Licensed clubs in remote Aboriginal communities. Australian and New Zealand journal of public health, 22(6), 679-684. 
d'Abbs, P., Ivory, B., Senior, K., Cunningham, T., Fitz, J. (2010). Managing alcohol in Tennant Creek, Northern Territory: an evaluation of the Tennant Creek Alcohol Management Plan and related measures to reduce alcoholrelated problems. A report prepared for the NT Department of Justice. Darwin: Menzies School of Health Research.

d'Abbs, P. (2011). Alcohol restrictions in Indigenous communities: necessary but not sufficient. Medical Journal of Australia, 194(10), 507-507.

Elliott, E., Latimer, J., Fitzpatrick, J., Oscar, J., Carter, M. (2012). There's hope in the valley. Journal of paediatrics and child health, 48(3), 190-192.

Gray, D., Saggers, S., Atkinson, D., Sputore, B.A., Bourbon, D. (2000). Beating the grog: an evaluation of the Tennant Creek liquor licensing restrictions. Australian and New Zealand journal of public health; 24:39-44.

Hudson, S. (2011). Alcohol restrictions in Indigenous communities and frontier towns: Centre for Independent Studies.

Joan Monica Maloney v The Queen [2013] HCA 28.

Margolis, S.A., Ypinazar, V.A., Muller, R. (2007). The impact of supply reduction through alcohol management plans on serious injury in remote indigenous communities in remote Australia: a ten-year analysis using data from the Royal Flying Doctor Service. Alcohol \& Alcoholism, 43(1), 104-110.

Martin, D., Brady, M. (2004). Human rights, drinking rights? Alcohol policy and Indigenous Australians. Lancet, 364, 1282-1283.

Marninwarntikura Fitzroy Women's Resource Centre (2018). Our Executive Team. Retrieved 12 June 2018 from https://www.mwrc.com.au/pages/our-executives.

Northern Territory Government (2017). Alcohol penalties and offences: residents. Retrieved $15^{\text {th }}$ March 2018

from https://nt.gov.au/law/alcohol/alcohol-penalties-and-offences-residents

Northern Territory Department of Treasury and Finance (2017). Penalties. Retrieved $15^{\text {th }}$ March 2018 from https://nt.gov.au/employ/money-and-taxes/taxes,-royalties-and-grants/territory-revenue-office/penalty-units

North Sydney Council (2017). Alcohol free areas and liquor accord. Retrieved $15^{\text {th }}$ March 2018 from https://www.northsydney.nsw.gov.au/Community_Services/Safety/Alcohol_Free_Areas_Liquor_Accord

Racial Discrimination Act 1975

Saggers, S., \& Gray, D. (1998). Dealing with alcohol: indigenous usage in Australia, New Zealand and Canada. Cambridge University Press.

Stronger Futures in the Northern Territory Act 2012

Smith, K., Langton, M., D'Abbs, P., Room, R., Chenhall, R., \& Brown, A. (2013). Alcohol management plans and related alcohol reforms. Retrieved $10^{\text {th }}$ October 2017 from https://www.indigenousjustice.gov.au/wpcontent/uploads/mp/files/publications/files/brief016.pdf

Senate Finance and Public Administration Legislation Committee (2017). Answers to questions on notice. Budget Estimates 2017-2018. Northern Territory - Alcohol Management Plan approval. Department of the Prime Minister and Cabinet, Canberra.

Senior, K., Chenhall, R., Ivory, B., Stevenson, C. Moving beyond the restrictions: the evaluation of the Alice Springs Alcohol Management Plan. Retrieved $10^{\text {th }}$ October 2017 from http://www.territorystories.nt.gov.au/bitstream/10070/218442/2/Vatskalis-110609Alcohol_restrictions_working_in_Alice_Springs_attachment.pdf

Queensland Liquor Act 1992

Queensland Government Demography and Indigenous Statistics Team. Alcohol Management Plan Review Breach of alcohol restrictions in Indigenous communities and associated contact with the criminal justice system. Retrieved $10^{\text {th }}$ October 2017 from https://www.datsip.qld.gov.au/resources/datsima/publications/policy/amp/amp-review.pdf

Queensland Government Department of Treasury and Trade (2013). Breach of alcohol restrictions in Indigenous communities and associated contact with the criminal justice system. Retrieved 15 March 2018 from https://www.datsip.qld.gov.au/resources/datsima/publications/policy/amp/ampreview.pdf

Tangentyere Council Northern Territory. Tangentyere Remote Area Night Patrol. Retrieved 10 ${ }^{\text {th }}$ October 2017 from http://www.aic.gov.au/media_library/conferences/crimpre/walker.pdf

Turner-Walker, J. (2012). Clash of the paradigms: Night patrols in remote central Australia. University of Western Australia. 
Wilson, M., Stearne, A., Gray, D., Saggers, S. (2010). Review of the harmful use of alcohol amongst Indigenous Australians. Australian Indigenous HealthInfoNet.

World Health Organization (WHO). Prevention and control of NCDs: priorities for investment. In: First Global Ministerial Conference on Healthy Lifestyles and Noncommunicable Disease Control. Moscow (RUS): WHO; 2011. 